\title{
EL ASESINATO DEL LEGADO OCTAVIO (163/2 a. C.): ALGUNAS PRECISIONES SOBRE LA TRADICION HISTORIOGRAFICA
}

The murder of legate Cn. Octavius in Laodicea (163/2 B. C.) was due to the whole town, and it was not the result of an individual action finally imputable to the regent Lysias, as historiographic tradition on behalf of Demetrius I maintains.

El asesinato del legado romano Gneo Octavio en Laodicea del Mar en $163 / 2$ y las consecuencias e implicaciones que supuso en esa coyuntura del reino seléucida presenta en nuestra tradición un aspecto sospechoso a causa de la manifiesta parcialidad de la fuente principal que nos informa al respecto, Polibio, y por lo tanto del resto de los testimonios que casi con toda seguridad derivan de aquél ${ }^{1}$. Los hechos que sucedieron a continuación del atentado tuvieron como culminación el acceso al poder de Demetrio I, que hasta esos momentos había estado viviendo en Roma como rehén, y la continuidad de la línea hereditaria que se había interrumpido tras Seleuco IV. Demetrio consiguió escapar de Roma gracias a la colaboración de algunas personalidades destacadas, probablemente miembros del círculo de los Escipiones entre los que se hallaba también Polibio ${ }^{2}$. Octavio había llegado a Siria tras una larga misión que le había llevado por todo el Oriente con la finalidad de revisar el cumplimiento de las cláusulas fijadas por el tratado de Apamea relativas al número de las fuerzas militares. Al parecer éstas habían sido transgredidas por lo que respecta a la flota y al mantenimiento de elefantes como medio de combate. En consecuencia, Octavio

1 Sobre las fuentes, H. Volkmann, "Demetrios I und Alexander I von Syrien", Klio 19, 1925, pp. 374-375.

2 Volkmann, art. cit., p. 380 ss. Es aceptado por E. Will, "Rome et les Seleucidesn, ANRW, I 1, p. 623 , n. 36. Presenta sus dudas al respecto E. Gruen, «Rome and the Seleucids in the Aftermath of Pydna*, Chiron 6, 1976, p. 83. Tambićn F. W. Walbank, A Historical Commentary on Polybius, III, Oxford 1979, p. 478 (donde se recogen algunas otras opiniones). 
ordenó dar muerte a los animales y prender fuego a las naves, provocando con ello una airada reacción popular que se vio concretada en la acción de un curioso personaje llamado Leptines, que dio muerte al legado cuando se encontraba en el gimnasio de la ciudad ${ }^{3}$. Dión Casio atribuye la responsabilidad del hecho al regente Lisias, que se había hecho cargo del reino tras la muerte de Antíoco IV, durante la minoría de edad del joven Antíoco V ${ }^{4}$. Polibio, por su parte, si bien no lo menciona expresamente, deja también traslucir esta versión cuando refleja el relato de las circunstancias de Siria en esos momentos por boca del padre adoptivo de Demetrio, un tal Diodoro, que había acudido a Roma por entonces para incitar a Demetrio a que se hiciera cargo de la situación aprovechando la favorable conyuntura que se le ofrecía ${ }^{5}$.

Sin embargo, si realizamos una lectura de los acontecimientos desde un punto de vista no interesado, dado que Polibio debió de emplear como fuente de información al mencionado Diodoro y debieron de influir poderosamente en su visión de lo sucedido sus simpatías evidentes hacia la persona de Demetrio, podemos llegar a conclusiones bien distintas ${ }^{6}$. Así el propio Polibio indica cómo Lisias envió una embajada a Roma tras el asesinato para tratar de despejar cualquier sospecha sobre la participación o implicación de los consejeros reales en el asunto ${ }^{7}$. Por otro lado, sabemos que Lisias enterró a Octavio, quizá en un intento de aminorar las consecuencias de lo ocurrido ${ }^{8}$. Ambas acciones no parecen encajar bien con su supuesta intervención en el asunto. Está, por otra parte, el contexto político general en que tuvieron lugar los hechos.

Efectivamente, Diodoro hace especial hincapié en la difícil situación en que se encontraban Lisias y sus partidarios en esos momentos, ya que existía un estado de desconfianza mutuo entre aquéllos y la multitud, situación que era la más idónea para el regreso de su ahijado Demetrio $^{9}$. De hecho sabemos que cuando Demetrio llegó al país provocó un fuerte movimiento en su favor y obtuvo con relativa facilidad la victoria, siendo aclamado a su entrada en Antioquía como salvador ${ }^{10}$.

3 App., Syr. 46. Sobre las cláusulas limitativas de la potencia scléucida en el tratado de Apamea, A. H. MacDonald y F. W. Walbank, "The Treaty of Apamea (188 B. C.): The Naval Clauses", JRS 59, 1969, p. 30 ss.

4 Zon., IX 25. Sobre la persona del regente, Walbank, Comm., III, p. 471.

5 Pol., XXXI 12.

6 P. Pédech, La méthode historique de Polybe, París 1964, pp. 271 y 364.

7 Pol., XXXI 11, 2.

8 App., Syr. 46.

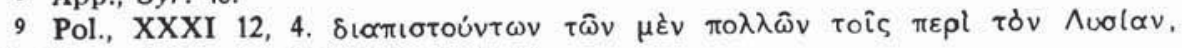

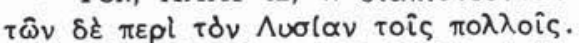

10 Jos., Ant. Ind. XII 389-390; I Macch. 7, 1-4. A. Bouché-Leclerq, Histoire des 
Estas circunstancias nos llevan a suponer una dirección diferente a los acontecimientos de la de que nuestras fuentes se hacen eco. Parece, en efecto, más probable a la vista de lo sucedido que la acción popular contra el legado romano desbordase a Lisias, que se vio incapaz de contener la reacción violenta a las medidas adoptadas por Octavio contra el poderío nacional seléucida, y por ello intentó exculparse ante Roma del mejor modo posible enviando una embajada para tal efecto. Esta oposición de Lisias a los deseos de la multitud le habrían hecho acreedor de una gran impopularidad, de la que se sirvieron los partidarios de Demetrio, como Diodoro. La llegada de este último debió de despertar entre la multitud, que se movía en estos momentos en medio de una cierta efervescencia antirromana, ciertas esperanzas, ya que se había escapado de Roma - no hay que olvidarlo- y por tanto traía consigo una aureola de antirromanismo que convenía perfectamente a la situación creada con el asesinato de Octavio. Además, Demetrio era hijo de Seleuco IV, hacia cuya política exterior Roma había mostrado cierta hostilidad, y ello pudo haber estado también presente en las mentes de muchos ${ }^{11}$.

La reacción de Demetrio fue, sin embargo, la contraria de la esperada y de manera inmediata buscó obtener el reconocimiento de Roma, llegando a solicitar una entrevista con los legados romanos que habían sido enviados al Oriente tras su huida de Roma, que le fue denegada. No obstante, persistió en su empeño y envió él mismo una embajada a Roma que, además de llevar una corona de oro de diez mil estateras, presentó ante el Senado al responsable directo del asesinato de Octavio, el ya citado Leptines, y a un agitador que había aprobado en público el hecho, un estrafalario personaje llamado Isócrates. El Senado le aceptó la corona, pero rechazó la entrega de los prisioneros, hecho que Polibio interpreta como la reserva por parte romana de su derecho al castigo para una mejor ocasión, a la espera de si las futuras acciones de Demetrio eran merecedoras de su aprobación ${ }^{12}$. Esta actitud de Roma, que ha suscitado muy diversas explicaciones de parte de algunos estudiosos $^{13}$, podría haber estado motivada simplemente por la inicial

Seleucides, reimpr. Aalen 1978, pp. 315 y 317, supone que se habrían sumado a Demetrio los partidarios de un tal Filipo, que había sido designado como tutor del rey niño por Antíoco IV en sus últimos momentos y hab́a mantenido con Lisias una lucha por el poder, resultando vencido.

11 Will, "Rome et les Sel.n, p. 617 ss.

12 Pol., XXXII 2-3; Diod., XXXI 28-30; App., Syr. 47.

13 Will, "Rome et les Sel.n, p. 624 ss., supone que en estos hechos se reflejarían las disputas existentes en Roma entre grupos políticos y senatoriales. Por su parte Gruen, "Rome and the Sel.n, p. 83 ss. y más adelante en The Hellenistic World and the Coming of Rome, Londres 1984, p. 664, pretende ver en los hechos una prueba 
suspicacia de Roma ante la política del nuevo rey, teniendo en cuenta sobre todo los fundamentos sobre los que había asentado su poder. En este sentido quizá conviene recordar que Roma solamente reconoció a Demetrio cuando ya no había otra solución posible tras la derrota del usurpador Timarco, a quien había prestado su apoyo ${ }^{14}$, lo que parece claramente indicativo del rechazo absoluto de Roma hacia la persona de Demetrio como monarca seléucida.

Por otra parte, parece que Demetrio intentó ejercer la represión en Laodicea, posiblemente a causa del asesinato de Octavio, acción de la que le hizo desistir el epicúreo Filónides ${ }^{15}$. Igualmente, cuando Polibio relata lo sucedido con los dos más directos responsables del asesinato, alude a cómo Leptines se acercó a Demetrio para tranquilizarle en este sentido y para que no decidiera nada contra los laodiceos ${ }^{16}$. Todo ello parece indicar que, efectivamente, el asesinato había sido un hecho que incidía de alguna manera en la responsabilidad colectiva de la ciudad y no fue solamente el resultado de una acción individual, como parece desprenderse del testimonio de Apiano ${ }^{17}$. De hecho, la misión de Leptines de "tranquilizar" a Demetrio parece también indicativa de la conciencia que existía del cambio que se había operado en Demetrio, en contra de las expectativas puestas en él. Las revueltas posteriores en su contra hablan claramente a favor de esta creciente impopularidad que debió de comenzar a forjarse a raíz de su decidido empeño en buscar el reconocimiento de Roma a toda costa ${ }^{18}$.

De esta forma, parece posible que la tradición favorable a Demetrio, cuya base reside en Polibio, haya distorsionado en alguna medida los hechos hasta el punto de querer atribuir el asesinato de Octavio a la instigación de Lisias y tratar de presentar las acciones de Demetrio como encaminadas a dar satisfacción y venganza a Roma ${ }^{19}$. En definitiva, se pretendía hacer recaer toda la responsabilidad de los hechos sobre las personas de los consejeros reales y en particular sobre la de Lisias, que sin duda representaba el obstáculo principal para el acceso de Demetrio al poder. Sin embargo, la lógica de la secuencia de los hechos nos lleva a suponer que las cosas sucedieron de otro modo, ya

\footnotetext{
más de la absoluta indiferencia de Roma respecto a los asuntos del reino seléucida. siendo las observaciones de Polibio en este sentido el resultado de su visión parcial de las cosas basadas en consideraciones hechas a posteriori.

14 Will, Histoire politique du monde hellénistique, Nancy 1982, II, pp. 367-368.

15 Walbank, Comm., III, p. 520, n. 3.

16 Pol., XXXI 3, 4.

17 App., Syr. 46. No parece que se pueda deducir de este texto la implicación de Lisias en el asesinato de Octavio como pretende Walbank, Comm., III, p. 478.

18 Pol., XXXI 33, 3-4.

19 Así lo presenta el testimonio de Dión Casio recogido en Zonaras, IX 25.
} 
que resulta poco imaginable que Lisias hubiera emprendido una acción contra Roma, asesinando a uno de sus legados, después de la experiencia sufrida por su rey Antíoco IV en Eleusis ante Popilio Lenas y el impacto psicológico que ella supuso ${ }^{20}$. Además, sus relaciones con Roma no habían sufrido ningún percance e incluso había contado con su respaldo en el acuerdo llevado a cabo con los judíos ${ }^{21}$. Por otra parte, el propio Polibio menciona la satisfacción que existía entre los consejeros reales por la decisión romana de no permitir el regreso de Demetrio, lo que posiblemente significaba a sus ojos que Roma prestaba su apoyo al reinado del joven monarca Antíoco V, por lo que no parece probable que en este estado de cosas llevasen a cabo un acto que podía tener consecuencias imprevisibles en este mismo sentido ${ }^{22}$. Por todo ello, quizá sea preferible suponer que la tradición historiográfica se ha inclinado una vez más de una forma descarada en favor de una de las partes en conflicto y, por tanto, ha hecho su aparición el consiguiente riesgo de deformación histórica o de exageración distorsionadora que tiende a explotar en forma claramente tendenciosa ciertos rasgos peculiares. La descripción de las personas de Leptines e Isócrates parece un buen ejemplo de esto último, pues, a pesar de que sin duda existía una base cierta en lo extravagante de ambos personajes, muy posiblemente el afán apologético de Polibio, que trataba de convertir lo que había sido el resultado de una acción popular en un mero acto de insania individual y de paso desacreditaba a dos adversarios políticos de Demetrio ${ }^{23}$, intervino de forma decisiva en su visión de los mismos.

\section{F. JAVIER GÓMEz Espelosin}

20 Sobre el asunto Will, Histoire, II, p. 344 ss.

Will, Histoire, II, p. 342.

22 Pol., XXXI 2, 10. También Gruen, art. cit., p. 80.

23 Así se denomina a Isócrates en Pol., XXXI 33, 5. 